\title{
SONG LYRICS AS A STIMULAN MEDIA IN WRITING SHORT STORIES FOR JUNIOR HIGH SCHOOL STUDENTS
}

\author{
Fauzi Rahman \\ Universitas Indraprasta PGRI \\ Supatmi \\ SMP Bina Pendidikan \\ Jl. K.H. Rafei RT 02.03, Nagrak, Gunungputri, Bogor \\ e-mail: fauzierachman20@yahoo.com
}

\begin{abstract}
The song is a work favored by all humans in the world. Songs can be enjoyed by all people, including teenagers who are still active in school. Because it is related to imagination, songs can certainly be a good medium when applied in the learning process in the classroom, especially in writing short stories. Therefore, this study aims to determine the effectiveness of song media in stimulating the ability to write short stories in students. This research is a quantitative research with Cluster Sampling method (group sample). This study used a posttest-only control group design, with the two groups: experimental class and control class which only final test results were taken (post test). The population in this study were students at one of the junior high schools in Jakarta, Indonesia (51 students). 25 students were positioned as the control class and 26 students as the experimental class. The results showed that the ability to write short stories through song media was effective in stimulating the ability to write short stories. This is based on the results of the $\mathrm{t}$-test, found $\mathrm{t}$-count $=2.73$ and $\mathrm{t}$-table $=2.01$. Because $\mathrm{t}$-count is greater than $\mathrm{t}$-table, then Ho is rejected, it can be concluded that the average learning outcomes of writing short stories that use song media are higher than the average learning outcomes of writing short stories that do not use song media.
\end{abstract}

Key Words: Song Lyrics, Short Stories, Writing, Junior High School.

Article History: Received: 18/09/2020; Revised: 15/10/2020; Accepted: 26/11/2020; Published: 31/12/2020

How to Cite (MLA 7th): Rahman, Fauzi, and Supatmi. "Song Lyrics as A Stimulan Media in Writing Short Stories for Junior High School Students." Hortatori Jurnal Pendidikan Bahasa dan Sastra Indonesia 4.2 (2020): 109-115. Print/Online. Copyrights Holder: Fauzi Rahman, Supatmi. First Publication: Hortatori Jurnal Pendidikan Bahasa dan Sastra Indonesia (2020).

This work is licensed under a Creative Commons Attribution-ShareAlike 4.0 International License.

\section{Pendahuluan}

Menulis merupakan kegiatan menyampaikan gagasan, pesan, informasi, atau perasaan secara tertulis kepada pembaca atau pihak lain. Menurut Dalman dalam kegiatan menulis, penulis haruslah menggunakan bahasa tulis yang sesuai standar bahasa tulis yang baik sebagai alat atau medianya. Artinya aktivitas menulis melibatkan beberapa unsur yaitu: penulis sebagai penyampaian pesan, isi tulisan, saluran media dan pembaca. Menulis merupakan salah satu dan keempat kemampuan dalam membaca selain mendengarkan, berbicara, dan membaca (Harmer).

Kegiatan menulis dapat dituangkan dalam beberapa wadah, baik berupa tulisan fiksi ataupun nonfiksi. Salah satu kegiatan menulis fiksi yaitu berupa penulisan cerpen. Cerpen atau cerita pendek adalah cerita yang menurut wujud fisiknya berbentuk pendek, yang habis dibaca sekitar sepuluh menit atau setengah jam, jumlah katanya sekitar 500-5000 kata (Kosasih). 
Jika dibandingkan dengan menulis novel, penulisan cerpen tentu akan lebih mudah. Oleh karena itu, cerpen lebih banyak digunakan oleh para penulis, khususnya yang pemula dalam mengungkapkan pengalaman empirisnya kepada khalayak dalam suatu cerita naratif. Sifat yang dimiliki oleh cerpen juga begitu ringan sehingga mampu menginventarisasi isu-isu yang tengah berkembang di masyarakat. Dengan begitu, cerpen sudah tentu dapat dijadikan refleksi dari kehidupan sosial di mana cerita tersebut ditulis. Sebagai karya sastra yang tidak terlalu panjang, cerpen yang baik biasanya memiliki penyampaian kata yang efektif, imajinatif, ekspresif, sehingga pesan dan keinginan penulisnya akan diterima oleh setiap pembaca yang menikmatinya.

Di Indonesia, penulisan cerita pendek terdapat di dalam kurikulum 2013 untuk siswa tingkat menengah pertama dan menengah atas. Hal ini menunjukkan bahwa seorang guru harus memiliki kemampuan yang baik dalam memberikan pengajaran terkait penulisan cerpen di dalam kegiatan belajar mengajar. Guru harus mampu memaknai pembelajaran, serta menjadikan pembelajaran sebagai ajang pembentukan kompetensi dan perbaikan kualitas pribadi peserta didik. Ada begitu banyak peran/keterampilan yang perlu dikuasai agar seorang guru menjadi guru yang baik seperti: mendidik, mengajar, membimbing, melatih, menasihati, memotivasi, menjadi model dan teladan, meneliti, mendorong kreativitas, membangkitkan visi, membawakan cerita, menjadi aktor, menjadi emansipator, menjadi evaluator, dan menjadi kulminator (Mulyasa),

Untuk meningkatkan kemampuan siswa dalam menulis cerpen memerlukan metode yang efektif dan efisien. Model pembelajaran merupakan seluruh rangkaian penyajian materi ajar yang meliputi segala aspek sebelum dan sesudah pembelajaran dilakukan guru, serta segala fasilitas yang terkait digunakan secara langsung dan tidak langsung dalam proses belajar mengajar. Salah satu model pembelajaran yang dapat meningkatkan kemampuan siswa dalam menulis cerpen adalah media lirik lagu.

Banyak media belajar yang dapat digunakan untuk memudahkan siswa dalam belajar seperti media pendidikan sederhana, video, lagu, televisi dan film. Agar proses pembelajaran tidak mengalami kesulitan, maka masalah perencanaan, pemilihan dan pemanfaatan media perlu dikuasai dengan baik oleh pengajar (Mulyasa). Dengan penggunaan media pembelajaran yang tepat, siswa dapat lebih mudah dalam mengaplikasikan dan memahami materi yang diterimanya. Oleh karena itu, seorang guru harus kreatif dan inovatif dalam membuat media pembelajaran yang tepat sasaran, agar siswa dapat menyerap materi pelajaran dengan maksimal.

Media memegang peranan penting dalam pembelajaran bahasa Indonesia. Dengan media yang sesuai, siswa dapat memahami penjelasan guru dengan mudah. Begitu juga dalam pembelajaran menulis cerpen, yaitu dengan menggunakan lirik lagu sebagai medianya. Melalui media lirik lagu. siswa diharapkan mampu memahami adanya suatu peristiwa yang terkandung di dalam lirik lagu. Selain adanya peristiwa paling tidak terdapat topik di dalam lagu tersebut yang dapat dijadikan ide untuk mengembangkan sebuah cerpen. Lagu merupakan rangkaian kata-kata yang disusun dan digunakan oleh seorang pencipta lagu untuk mengungkapkan ekspresi dan pikirannya, dengan menggunakan irama serta diiringi melodi ataupun musik (Rahman dan Anto; Rahman).

Pembelajaran menulis cerpen dimulai dengan adanya ide. Ide adalah gagasan awal yang menjadi dasar dalam penulisan cerpen. Bagi penulis pemula terkadang sulit untuk menemukan ide yang menarik untuk dikembangkan dalam penulisan cerpen. Cara yang dapat menjadi alternatif untuk membantu siswa dalam menentukan ide adalah dengan menggunakan media lagu. Media lagu dalam hal ini yaitu lirik dan video klip yang ditampilkan dalam pembelajaran menulis cerpen.

Berdasarkan pengamatan awal, penggunaan media lirik lagu belum pernah diterapkan dalam pembelajaran menulis cerpen pada siswa SMP. Hal ini sesuai dengan hasil penelitian dari Ratnaningsih (2014) yang menyatakan hasil yaitu bahwa dari segi pemanfaatan strategi pembelajaran, sebagian guru (54\%) masih bermasalah dalam menggunakan strategi pembelajaran inovatif, dan dari segi pemanfaatan lagu, mayoritas guru (86\%) menyatakan tidak pernah menggunakan lagu dalam pembelajaran.

Lagu yang memiliki durasi waktu relatif singkat diharapkan dapat dijadikan sebagai media yang efektif dan sesuai dengan pembelajaran menulis cerpen di kelas. Selain itu, lagu tidak memerlukan waktu yang lama dalam mendengarnya maupun membacanya, sehingga waktu pembelajaran dapat disesuaikan dengan alokasi waktu dalam pembelajaran.

Penelitian ini bertujuan untuk membuat siswa terstimulasi kemampuan menulisnya, khususnya cerita pendek melalui media lirik lagu. Melalui lagu, baik secara simakan maupun bacaan (lirik), membuat siswa akan lebih antusias dalam mengikuti pembelajaran. Oleh karena itu, keterampilan menulis cerpen 
dengan menggunakan media lagu diasumsikan sangat berpengaruh dalam pembelajaran menulis cerpen siswa SMP.

\section{Metode}

Metode yang digunakan di dalam penelitian ini adalah metode eksperimen dengan desain penelitian "Posttest-Only Control Design".. Pemilihan metode eksperimen ini karena peneliti ingin mengetahui secara pasti pengaruh penggunaan media lagu terhadap kemampuan menulis cerpen. Teknik pengambilan sampel pada penelitian ini dilakukan secara random. Pengumpulan data menggunakan instrumen penelitian dan analisis data menggunakan statistik.

Metode eksperimen merupakan suatu metode yang dipakai untuk mencari dampak dari perlakuan tertentu terhadap suatu objek dalam kondisi yang terkendalikan (Sugiyono). Dalam hal ini, perlakuan ditujukan kepada siswa SMP yang menulis cerita pendek menggunakan stimulasi media lagu. Eksperimen menggunakan media lagu ini memiliki pengukuran dampak, sehingga dapat menyimpulkan ada atau tidaknya perubahan setelah percobaan. Dengan kata lain, metode eksperimen merupakan cara untuk untuk mencari hubungan kausalitas antara dua faktor yang secara sengaja diciptakan oleh peneliti dengan cara menyingkirkan faktor-faktor lain yang dianggap tidak diperlukan.

Tabel 1

Desain Penelitian

\begin{tabular}{|lll|}
\hline & $\mathrm{R}$ & $\mathrm{X}$ \\
$\mathrm{O}_{2}$ & $\mathrm{R}$ & \\
$\mathrm{O}_{4}$ & & \\
\hline
\end{tabular}

Dalam desain penelitian ini ada dua kelompok siswa yang masing-masih dipilih secara acak. Kelompok siswa yang mendapatkan perlakuan dengan diberikan metode lagu (X1) dan kelompok lain yang tidak diberikan perlakuan (X2). Kelompok siswa yang diberikan perlakuan disebut dengan istilah kelas eksperimen, sedangkan kelompok siswa yang tidak diberikan perlakuan disebut dengan istilah kelas kontrol. Pengaruh adanya perlakuan adalah (O1:O2). Dalam penelitian yang sebenarnya, pengaruh perlakuan dianalisis dengan uji beda menggunakan statistik t-test. Jika terdapat perbedaan yang signifikan antara kekelas eksperimen dengan kelas kontrol, maka perlakuan yang diberikan memiliki pengaruh yang signifikan.

\section{Hasil dan Diskusi}

Lagu dapat dipergunakan dalam berbagai jenis aktivitas pembelajaran, seperti sebagai penghangat suasana, pengisi transisi antara dari satu keguatan ke kegiatan lain, penutup kegiatan, memperkenalkan bahasa baru, berlatih bahasa, memperbaiki bahasa, mengubah suasana/ mood, menarik perhatian, untuk menyalurkan energi siswa yang berlebih dan sebagainya (Nurhayati; Pellitteri). Dalam penelitian ini, lagu digunakan sebagai media perangsang kreativitas siswa untuk menulis cerita pendek (Schoepp).

Setelah proses pembelajaran menulis cerpen terhadap kelas yang diberikan media stimulan lirik lagu (kelas eksperimen) dengan kelas yang diberikan pembelajaran konvensional (ceramah materi) atau kelas kontrol, didapat nilai hasil postest tersebut.

Table 2 Post-test results processing data on the ability of students in writing short stories

\begin{tabular}{lcccc}
\hline No & $\begin{array}{c}\text { Kelas Eksperimen } \\
\left(\mathbf{X}_{\mathbf{1}}\right)\end{array}$ & $\begin{array}{c}\text { Kelas } \\
\text { Kontrol }\left(\mathbf{X}_{\mathbf{2}}\right)\end{array}$ & $\mathbf{X}_{\mathbf{1}}$ & $\mathbf{X}_{\mathbf{2}}$ \\
\hline $\mathbf{1 .}$ & 50 & 54 & 2500 & 2916 \\
$\mathbf{2 .}$ & 72 & 59 & 5184 & 3481 \\
$\mathbf{3 .}$ & 97 & 54 & 9409 & 2916 \\
$\mathbf{4 .}$ & 92 & 62 & 8464 & 3844 \\
$\mathbf{5 .}$ & 59 & 77 & 3481 & 5929 \\
$\mathbf{6 .}$ & 72 & 74 & 5184 & 5476 \\
$\mathbf{7 .}$ & 80 & 62 & 6400 & 3844 \\
$\mathbf{8 .}$ & 82 & 62 & 6724 & 3844 \\
$\mathbf{9 .}$ & 85 & 39 & 7225 & 1521
\end{tabular}


112 Song Lyrics As a Stimulan Media in Writing Short Stories for Junior High School Students

\begin{tabular}{|c|c|c|c|c|}
\hline 10. & 80 & 62 & 6400 & 3844 \\
\hline 11. & 47 & 34 & 2209 & 1156 \\
\hline 12. & 90 & 72 & 8100 & 5184 \\
\hline 13. & 85 & 39 & 7225 & 1521 \\
\hline 14. & 69 & 44 & 4761 & 1936 \\
\hline 15. & 59 & 72 & 3481 & 5184 \\
\hline 16. & 90 & 75 & 8100 & 5625 \\
\hline 17. & 75 & 97 & 5625 & 9409 \\
\hline 18. & 62 & 85 & 3844 & 7225 \\
\hline 19. & 95 & 44 & 9025 & 1936 \\
\hline 20. & 70 & 52 & 4900 & 2704 \\
\hline 21. & 62 & 39 & 3844 & 1521 \\
\hline 22. & 67 & 90 & 4489 & 8100 \\
\hline 23. & 67 & 70 & 4489 & 4900 \\
\hline 24. & 75 & 87 & 5625 & 7569 \\
\hline 25. & 80 & 46 & 6400 & 2116 \\
\hline 26. & 62 & - & 3844 & - \\
\hline Total & 1924 & 1551 & 146.932 & 103.701 \\
\hline
\end{tabular}

Berdasarkan uji liliefors yang dilakukan terhadap sampel dua puluh enam orang siswa di kelas eksperimen. Didapat Lo maksimal yaitu 0.1547 sedangkan Lt pada taraf signifikansi 0.05 didapat sebesar 0.173 .

Pada sampel siswa kelas kontrol dua puluh lima siswa didapatkan Lo maksimal sebesar 0.0915, sedangkan Lt pada tarif signifikansi 0.05 sebesar 0.173. Dapat disimpulkan bahwa kedua Lo < Lt. Maka, sampel berdistribusi normal.

Table 3 Uji Normalitas

\begin{tabular}{lcccl}
\hline $\mathbf{X}$ & $\mathbf{N}$ & $\mathbf{L o}$ & $\mathbf{L t}$ & Information \\
\hline Experimental Class & 25 & 0,1547 & 0,173 & Normal \\
\hline Control Class & 26 & 0,0915 & 0,173 & Normal \\
\hline
\end{tabular}

Pada uji persyaratan analisis (uji homogenitas), hasil yang didapat yaitu $\mathrm{F}_{\text {hitung }}=1,709$ dan $\mathrm{F}_{\text {tabel }}$ 1,939. Karena $F_{\text {hitung }} \leq F_{\text {tabel }}$, maka $H_{o}$ diterima (homogen), yang berbunyi: "Tidak terdapat perbedaan varians 1 dengan varians 2 "

Dalam penelitian ini, peneliti menggunakan cara uji: varians terbesar dibandingkan varians terkecil didapat yaitu $F_{\text {hitung }}=1,709$ dan $F_{\text {tabel }}=1,939$. Oleh karena itu, dapat disimpulkan bahwa kedua kelas tersebut adalah homogen.

Table 4 Uji Homogenitas

\begin{tabular}{|c|c|c|c|c|c|c|}
\hline $\mathrm{S}^{2}$ & $F_{\text {count }}$ & $\mathrm{F}_{\text {table }}$ & $\mathrm{N}_{1}$ & $\mathrm{~N}_{2}$ & usion & Concl \\
\hline 182,2 & 1,70 & 1,939 & 26 & 25 & geny & Homo \\
\hline
\end{tabular}

Analisis data dengan uji-t merupakan upaya untuk melihat perbedaan kemampuan menulis cerpen siswa SMP. Jika terdapat perbedaan yang signifikan, berarti terdapat pengaruh penggunaan media lagu terhadap kemampuan menulis cerpen siswa .

Jika tidak terdapat perbedaan, berarti tidak ada pengaruh penggunaan media lagu terhadap kemampuan menulis cerpen siswa. Untuk melihat perbedaan antara hasil kelompok eksperimen dengan kelas kontrol yang diteliti, digunakan uji-t. Selanjutnya, data tersebut dibandingkan dengan nilai kritis pada tabel.

Kriteria pengujian hipotesis ini adalah

Terima $\mathrm{H}_{\mathrm{o}}$ jika $\mathrm{t}_{\text {hitung }}<\mathrm{t}_{\text {tabel. }}$. Maka tidak terdapat pengaruh

Tolak $\mathrm{H}_{\mathrm{o}}$ jika $\mathrm{t}_{\text {hitung }}>\mathrm{t}_{\text {tabel. }}$. Maka terdapat pengaruh.

Dalam tabel berikut, terlihat perbedaan nilai t hitung dengan $\mathrm{t}$ tabel.

Table 4 Hasil Pengujian Hipotesis (t-Test) 


\begin{tabular}{clll}
\hline \multicolumn{1}{c}{ Between groups } & $\mathrm{t}_{\text {hitung }}$ & $\mathrm{t}_{\text {tabel }} 5 \%$ & Information \\
\hline $\begin{array}{l}\text { Kemampuan menulis cerpen siswa pada pembelajaran dengan } \\
\text { media lagu dan yang tidak }\end{array}$ & 2,73 & 2,01 & Berbeda \\
\hline
\end{tabular}

Hasil tersebut dapat digambarkan dalam daerah kritis penerimaan $\mathrm{H}_{\mathrm{o}}$ dari uji $\mathrm{t}$ sebagai berikut:

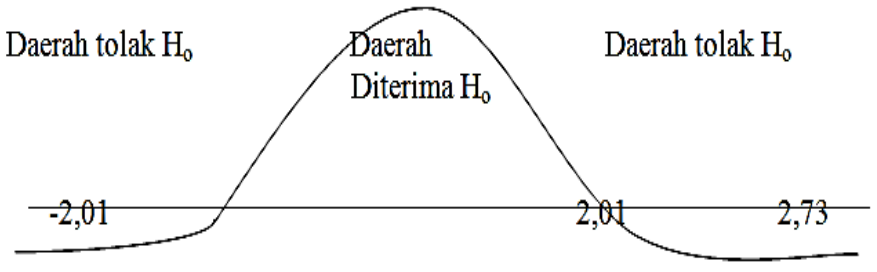

Hasil uji memperoleh nilai $\mathrm{t}_{\text {hitung }}>\mathrm{t}_{\text {tabel }}(2,73>2,01)$ pada taraf signifikansi $5 \%$, maka $\mathrm{H}_{\mathrm{o}}$ ditolak. Artinya terdapat perbedaan kemampuan menulis cerpen antara kelompok siswa yang diberi pembelajaran dengan media lagu dan yang tidak menggunakan media lagu. Hal ini menunjukkan bahwa pembelajaran dengan media lagu berpengaruh terhadap hasil belajar siswa dalam menulis cerpen dan hipotesis diterima. Artinya pembelajaran dengan menggunakan media lagu lebih baik dalam meningkatkan kemampuan menulis cerpen siswa.

Hasil nilai yang didapat yaitu $t_{\text {hitung }}=2,73$ dan $t_{\text {tabel }}=2,01$ dalam taraf nyata 0,05 . Hal ini disebabkan $t_{\text {hitung }}$ lebih besar dari $t_{\text {tabel, }}$, berarti $H_{o}$ ditolak. Dengan demikian, dapat disimpulkan bahwa hipotesis penelitian terdapat pengaruh penggunaan media lagu terhadap kemampuan menulis cerpen siswa, diterima. Oleh karena itu, perangsangan menggunakan media musik ataupun lirik lagu pada subjek penelitian, dalam hal ini adalah pada kelompok eksperimen dan kelompok kontrol mengalami peningkatan yang berbeda, peningkatan kecerdasan di kelompok eksperimen lebih tinggi dibandingkan dengan kelompok kontrol.

Dengan hasil tersebut, dapat dikatakan bahwa lagu dapat menjadi sarana yang efektif dalam pembelajaran menulis. Efektivitas lagu sebagai media dimaksimalkan dengan prinsip link and match (hubungan dan kesesuaian). Peran imajinasi dalam lagu juga memberikan kontribusi yang cukup besar pada keberhasilan pembelajaran menulis. Imajinasi yang terbangun baik membantu siswa dalam menggali pengalaman hidup, mengorganisasikannya dan memberikan respons dalam bentuk simbol-simbol verbal yang baik (Trimantara; Leahy dan Sweller)

Pemilihan lagu dengan lirik-lirik yang puitis dapat membantu siswa dalam memperoleh pembelajaran kosakata. Proses ini dilakukan melalui imajinasi dengan stimulasi lagu. Pengembangan kosakata yang dimaksudkan di sini memiliki definisi yang lebih dari penambahan kosakata secara mendasar, tetapi lebih pada penanaman konsep-konsep baru dalam susunan yang lebih baik. Sugesti yang ditimbulkan melalui lagu dapat menstimulasi dan mengkondisikan siswa, sehingga siswa dapat memberikan respon secara spontan. Respon yang diberikan siswa tersebut tentunya berdampak positif pada kreativitas, imajinasi, serta daya bernalarnya. Respon yang ditunjukkan oleh siswa juga dapat muncul berupa kemampuan menggali pengalaman empirisnya atau mengingat kembali fakta-fakta, kejadian-kejadian, hingga kenangan-kenangan yang mereka temui. Dari pengalaman yang telah digali tersebut, siswa kemudian mampu mengorganisasikannya, serta memberikan tanggapan berupa gagasan-gagasan maupun konsep-konsep baru mengenai fakta-fakta tertentu. Metode sugesti imajinasi ini memungkinkan proses pembelajaran dapat berlangsung dengan baik, sehingga siswa memiliki cukup bahan untuk menulis suatu karangan (Trimantara).

Lirik dan lagu dapat memberikan dampak positif bagi siswa (Greitmeyer). Melalui media lagu diharapkan dapat menarik minat serta merangsang imajinasi siswa. Minat siswa yang sudah muncul dapat mempengaruhi suasana hati, menimbulkan semangat, ketenangan, serta dapat mengembangkan kreativitas siswa dalam berkarya. Media ini memiliki fungsi yang tidak hanya memiliki aspek yang menyenangkan saja, tetapi juga dapat menekankan arti serta komunikasi yang ada di dalam lirik yang dihasilkannya (Nurmaili). 
Pada akhirnya, menulis cerita pendek pada prosesnya menggunakan kedua otak (kirikanan), menghubungkan antara kata, kalimat, paragraf, maupun antarperistiwa yang disusun secara logis agar dapat dipahami (Wong et al.). Proses ini mendorong seorang penulis cerpen harus berpikir secara sistematis dan logis sekaligus kreatif serta imajinatif. Menulis secara umum maupun menulis cerpen secara khusus tidak ubahnya dengan melukis. Penulis cerpen harus memiliki ide dalam menuangkan pikirannya. Kendati secara teknik ada ketentuan yang dapat diikutinya, tetapi wujud yang akan dihasilkan itu sangat bergantung pada kepiawaian si penulis. Banyak orang mempunyai ide-ide bagus di benaknya sebagai hasil dari pengamatan, penelitian, diskusi, atau membaca. Akan tetapi, begitu ide tersebut dibuat secara tertulis, laporan itu terasa amat kering, kurang menggigit, dan membosankan. Selain itu, beberapa orang yang baru membuat cerpen akan didapati karya dengan gaya bahasa yang digunakan monoton, diksinya kurang tepat dan tidak mengena sasaran, serta variasi kata dan kalimat kering.

Dalam menulis, seseorang butuh inspirasi, ide, atau informasi untuk tulisannya. Hal tersebut dapat diperoleh dari berbagai sumber, antara lain : majalah, surat kabar, jurnal atau laporan, radio, televisi, ceramah, pidato, wawancara, dan tentu saja lagu. Dengan media lagu khususnya, menulis dari sumber tersebut merupakan menulis berdasarkan kemampuan menyimak jika lagu tersebut didengar, maupun membaca jika liriknya dibaca. Melalui dua kegiatan tersebut, siswa yang menjadi objek pebelajar tidak hanya memperoleh ide atau informasi untuk tulisannya, tetapi juga menginspirasi penyajian dan struktur penyampaian lisan yang menarik hatinya, yang berguna untuk aktivitas menulisnya.

\section{Simpulan}

Berdasarkan hasil penelitian eksperimen yang dilakukan pada kelas VIII SMP menunjukkan bahwa terdapat pengaruh media lagu terhadap kemampuan menulis cerpen siswa. Dari hasil rata-rata nilai kelas eksperimen sebesar 74 sedangkan nilai rata-rata kelas kontrol sebesar 62,04 dan hasil uji t, didapat $t_{\text {hitung }}=2,73$ dan $t_{\text {tabel }}=2,01$. Karena $t_{\text {hitung }}$ lebih besar dari $t_{\text {tabel }}$, maka $H_{o}$ ditolak. Hasil uji memperoleh nilai $t_{\text {hitung }}>t_{\text {tabel }}(2,73>2,01)$ pada taraf signifikansi $5 \%$. Hasil nilai yang didapat yaitu $t_{\text {hitung }}=2,73$ dan $\mathrm{t}_{\text {tabel }}=2,01$ dalam taraf nyata 0,05 . Hal ini disebabkan $\mathrm{t}_{\text {hitung }}$ lebih besar dari $\mathrm{t}_{\text {tabel, }}$, berarti $\mathrm{H}_{\mathrm{o}}$ ditolak. Berdasarkan hasil analisis diketahui bahwa Kemampuan Menulis Cerpen melalui Media Lagu terdapat pengaruh signifikan pada siswa SMP. Artinya, media lirik lagu dapat menstimulasi kemampuan siswa yang membaca/mendengarnya sehingga lebih mampu mengoptimalkan kemampuannya dalam penulisan cerita pendek.

Saran pada penelitian ini diarahkan pada guru di kelas. Bagi guru sebagai fasilitator pembelajaran, sebaiknya selalu inovatif dan kreatif dalam merancang stragtegi pembelajaran, khususnya dalam mata pelajaran Bahasa Indonesia. Penggunaan media lagu bagi siswa dalam pembelajaran cerpen dapat menstimulasi kreativitas mereka, karena lagu merupakan hal yang sangat dekat dengan anak-anak di zaman sekarang.

\section{Ucapan Terima Kasih}

Terima kasih diucapkan kepada beberapa pihak yang telah mendukung terselesaikannya penelitian ini. Semoga penelitian ini tepat sasaran.

\section{Daftar Rujukan}

Dalman. Keterampilan Menulis. Rajawali Press, 2014.

Greitmeyer, T. "Effects of songs with prosocial lyrics on prosocial thoughts, affect, and behavior." Journal of Experimental Social Psychlogi 45.1 (2009): 86-90.

Harmer, Jeremy. How To Teach Writing. Graha Ilmu, 2014.

Kosasih, E. Dasar-Dasar Keterampilan Bersastra. CV Yrama Widya, 2012.

Leahy, W., dan J. Sweller. "The imagination effect increases with an increased intrinsic cognitive load." The imagination effect increases with an increased intrinsic cognitive load 22. 2 (2008): 273-83. 
Mulyasa, E. Menjadi Guru Profesional. Rosdakarya, 2013.

Nurhayati, L. "Penggunaan Lagu Dalam Pembelajaran Bahasa Inggris Untuk Siswa SD; Mengapa dan Bagaimana." Majalah Ilmiah Pembelajaran 5.1 (2009).

Nurmaily, E. "Respon Mahasiswa Terhadap Penugasan Musikalisasi Puisi Melalui Media Sosial." Bahasa dan Seni: Jurnal Bahasa, Sastra, Seni, dan Pengajarannya 46.1 (2018).

Pellitteri, J. "The Consultant's Corner:" Music Therapy in the Special Education Setting"." Journal of Educational and Psychological Consultation 11.3-4 (2011): 379-91.

Rahman, Fauzi. "Persepsi Sufistik Lirik Lagu 'Suci Dalam Debu' Melalui Analisis Strata Norma." LiNGUA 13.1 (2018): 35-45.

Rahman, Fauzi, dan Puji Anto. "Analisis Lirik Lagu dan Aplikasinya dalam Pembelajaran Gaya Bahasa serta Puisi di Sekolah Dasar." Jurnal Inovasi Pendidikan Dasar 1.1 (2015): 9-14.

Schoepp, K. "Reasons for using songs in the ESL/EFL classroom." The Internet TESL Journal 7.2 (2001): $1-4$.

Sugiyono. Metode Penelitian Pendidikan: Pendekatan Kuantitatif, Kualitatif, dan R \& D. Alfabeta, 2015.

Trimantara, P. "Metode Sugesti-Imajinasi dalam Pembelajaran Menulis dengan Media Lagu." Jurnal Pendidikan Penabur 5.1 (2005): 1-15.

Wong, A. C., et al. "An early electrophysiological response associated with expertise in letter perception." Cognitive, Affective, \& Behavioral Neuroscience 5.3 (2005): 306-18. 